
\title{
High Resolution TEM Investigations and TDA Analysis of Zinc Alloy with Strontium Addition
}

\author{
K. Labisz*, M. Krupiński, M. Pawlyta, K. Matus, M. Kremzer and K. Dopierała \\ Division of Materials Processing Technology, Management and Computer Techniques in Materials Science, \\ Institute of Engineering Materials and Biomaterials, Silesian University of Technology, \\ S. Konarskiego 18A, 44-100 Gliwice, Poland
}

\begin{abstract}
In this paper there are presented results of high resolution transmission electron microscope investigation concerning the structure of the $\mathrm{Zn}-\mathrm{Al}-\mathrm{Si}$ cast zinc alloy with $\mathrm{Sr}$ addition for crystal structure refinement after thermoderivative analysis performed using the universal metallurgical simulator and analyzer platform. The thermoderivative analysis allows to determine the specific points of the solidifying alloy, which is helpful for phase determination and proper heat treatment condition determination, allowing to reduce the energy costs and obtaining higher mechanical and functional properties. Using transmission electron microscopy, especially selected area diffraction method appliance it was possible to determine the phases occurring in the alloy in the state after chemical composition modification as well as after appliance of very precisely controlled cooling rate. The morphology and size of the microstructure of micro-sized eutectic was possible to determine as well the lattice parameters of the Zn $\alpha$-phase. Particularly the overview will be also directed on the high resolution transmission electron microscope to achieve good insight into the structural changes on the atomic scale.
\end{abstract}

DOI: 10.12693/APhysPolA.130.823

PACS/topics: 68.37.Og, 81.70.Pg, 61.66.Dk

\section{Introduction}

The obtained cast microstructure directly affects the mechanical and technological properties of the final products, therefore, an important factor leading to the improvement of the cast quality is the appropriate use of knowledge concerning the crystallization process during solidification in order to control and optimize the structure and influence of the alloying additives. Zn alloys with aluminium addition tend to cast shrinkage, which is possible to compensate by introducing alloying element as Sr, improving fluidity, castability and the tendency to hot cracking. By adding strontium there occurs refinement of the dendrite structure followed by heterogeneous nucleation on the $\mathrm{Al}_{2} \mathrm{Sr}$ phase [1-4]. In the work [5] there was confirmed that the mechanical properties of the $\mathrm{Zn}$ $\mathrm{Al}$ alloy primarily affect the distance between dendrites arms, instead of the grain size. Primarily the dendrite arm spacing and distribution of intermetallic phases influences the mechanical properties of the $\mathrm{Zn}-\mathrm{Al}$ alloys, instead of the grain size [6-10].

\section{Experimental procedure}

Effect of cooling rate on the crystallization kinetics and microstructure of the cast $\mathrm{ZnAlCu}$ alloys was investigated based on the model casts (Table I) with strontium addition. The casts were performed in resistance furnace. Mass concentration of the alloy after casting with $\mathrm{Sr}$ addition was confirmed using the chemical composition analysis carried out using the procedure OES ICP on the device ULTIMA 2 Jobin-YVON. From the material

\footnotetext{
*corresponding author; e-mail: krzysztof.labisz@polsl.pl
}

cast into the metal molds, samples for thermo-derivative analysis were prepared with $\varnothing 30 \mathrm{~mm}$ in diameter and a height of $35 \mathrm{~mm}$. The thermo-derivative analysis for the investigated alloys with alloying additives was performed using the graphite crucible by appliance of the metallurgical universal metallurgical simulator and analyzer (UMSA) equipped with dedicated software for control and calculation. The samples were cooled down by forced cooling using compressed argon.

TABLE I

Chemical composition of the model casts.

\begin{tabular}{c|c}
\hline \hline Sample & $\begin{array}{c}\text { Elements included in the chemical composition } \\
\text { of the model casts }\end{array}$ \\
\hline Cast 1 (B) & $\begin{array}{c}\mathrm{ZnAlCuSr}(\text { content \% mass.) } \\
\mathrm{Al} 0.96, \mathrm{Cu} 1, \mathrm{Sr} 1.02, \text { rest } \mathrm{Zn}\end{array}$ \\
Cast $2(\mathrm{G})$ & $\begin{array}{c}\mathrm{ZnAlCu}(\text { content \% mass.) } \\
-\mathrm{Al} 0.98, \mathrm{Cu} 1, \text { rest } \mathrm{Zn}\end{array}$
\end{tabular}

In order to determine the relationship between the crystallization kinetics and the chemical composition, microstructure and properties of the Sr modified zinc alloy, the following tests were performed:

- thermo-derivative analysis of the investigated $\mathrm{Zn}$ alloys tested before and after modification with different cooling rates at the temperature range of $T_{\text {liq }}$ and $T_{\text {sol }}$ as well as $0.2^{\circ} \mathrm{C} \mathrm{s}^{-1}$ (forced cooling of the alloy with compressed argon);

- macrostructure by light microscopy MEF4A;

- thin foils and phase identification were made on the high resolution transmission electron microscope (HRTEM) Titan 80-300 with the scanning 
mode STEM, equipped with energy dispersive spectroscopy (EDS) detector for chemical composition investigations.

\section{Investigation results}

In Fig. 1 there is presented the microstructure of the $\mathrm{ZnAlCu}$ alloy with strontium addition cooled with rates of $c a .0 .2{ }^{\circ} \mathrm{C} \mathrm{s}^{-1}$. The desired cooling rate of $0.2^{\circ} \mathrm{C} \mathrm{s}^{-1}$ was obtained by cooling of the alloy from the temperature of $450^{\circ} \mathrm{C}$ with argon flowing through the cooling nozzle placed in the inductor. Increase of the cooling rate causes microstructure refinement and morphology change of the $\alpha$ phase. The phase marked as \#1 is the Sr containing phase $\mathrm{Al}_{2} \mathrm{Sr}$.

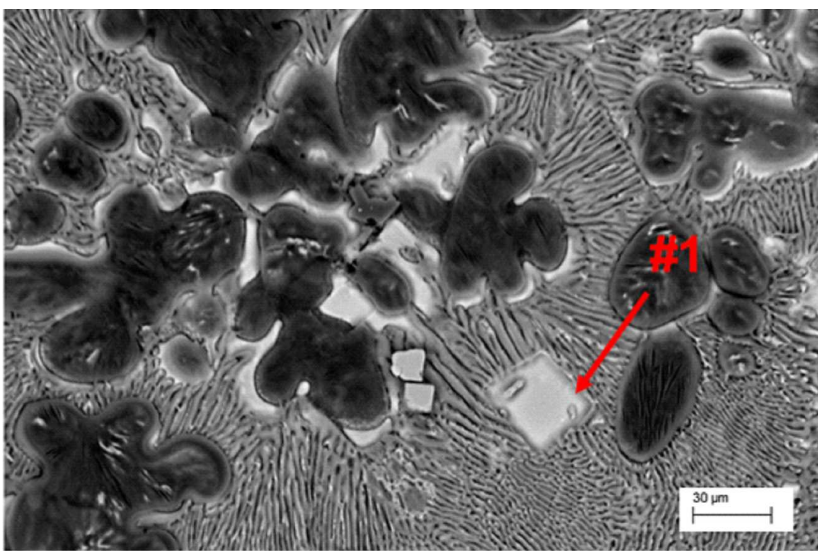

Fig. 1. SEM microstructure of the $\mathrm{Zn}-\mathrm{Al}-\mathrm{Cu}$ alloy modified with $\mathrm{Al}-\mathrm{Sr}$ addition: $\# 1-\mathrm{Al}_{2} \mathrm{Sr}$.
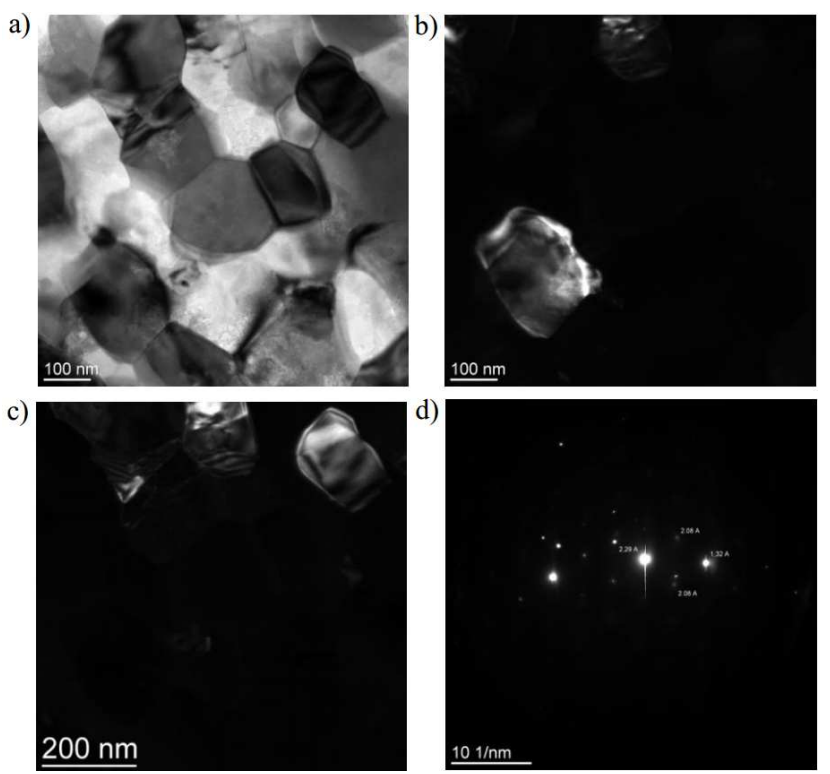

Fig. 2. Subgrains occurred in the alloy structure after Sr addition: (a) bright field, (b) dark field from the (200) reflection, (c) dark field from the (220) reflection, (d) diffraction pattern from the area presented on Fig. 2a, TEM.
The obtained results based of the microstructure investigation using HRTEM (Fig. 2) have revealed differences concerning structure in the submicrometric range of pure zinc and zinc with strontium addition. Metallographic investigations of the $\mathrm{Zn}-\mathrm{Al}-\mathrm{Cu}$ alloy modified with $\mathrm{Sr}$ in the as cast state reveals a dendritic morphology of the $\alpha$ phase, the eutectic $\alpha+\alpha^{\prime}$ and Sr precipitations as the base for heterogeneous nucleation during the solidification process of the alloy. For phase determination of the structure of the surface layer diffraction pattern analysis of the investigated areas has allowed to identify the $\mathrm{Zn} \eta$ phase (Fig. 2d) as a hexagonal phase of the $P 63 / m m c$ space group with the $d$-spacing of $a=b=0$. $2748 \mathrm{~nm}$ and $c=0.5167 \mathrm{~nm}$, which is more the lattice parameter values found in the literature for $\mathrm{Zn}$ phase equal to $a=b=0.2665 \mathrm{~nm}$ and $c=0.4947 \mathrm{~nm}$, and $c a .3 .1 \%$ larger $a, b$ lattice parameters compared to the literature data as well as $c a$. $4.5 \%$ more than the lattice parameter $c$ presented in the literature data. The $c d$-spacing with $4.5 \%$ enhancement is a measurable value which can be taken into account for the structure reinforcement of the $\mathrm{Zn}$ alloys with $\mathrm{Sr}$ addition.

Based on TEM investigations it was found that the sub-grains are in the size range between 100 and $150 \mathrm{~nm}$ for the $\mathrm{Sr}-\mathrm{Zn}$ alloy (Fig. 2b and c), whereas in the $\mathrm{Zn}$ alloy without strontium the size is higher - in the range up to $200-300 \mathrm{~nm}$, that is $c a$. $100 \%$ smaller than the non-modified material. The structure confirmed on the atomic scale using the HRTEM confirms that also a relative low dislocation density occurs.

TEM investigations presented in Fig. 3 have confirmed the occurrence of the $\mathrm{Al}_{2} \mathrm{Sr}$ phase present in the investigated $\mathrm{Zn}$ alloy matrix (STEM). The size of the $\mathrm{Al}_{2} \mathrm{Sr}$ phase particles is up to $1 \mu \mathrm{m}$ embedded in the $\alpha-\mathrm{Zn}$ matrix.
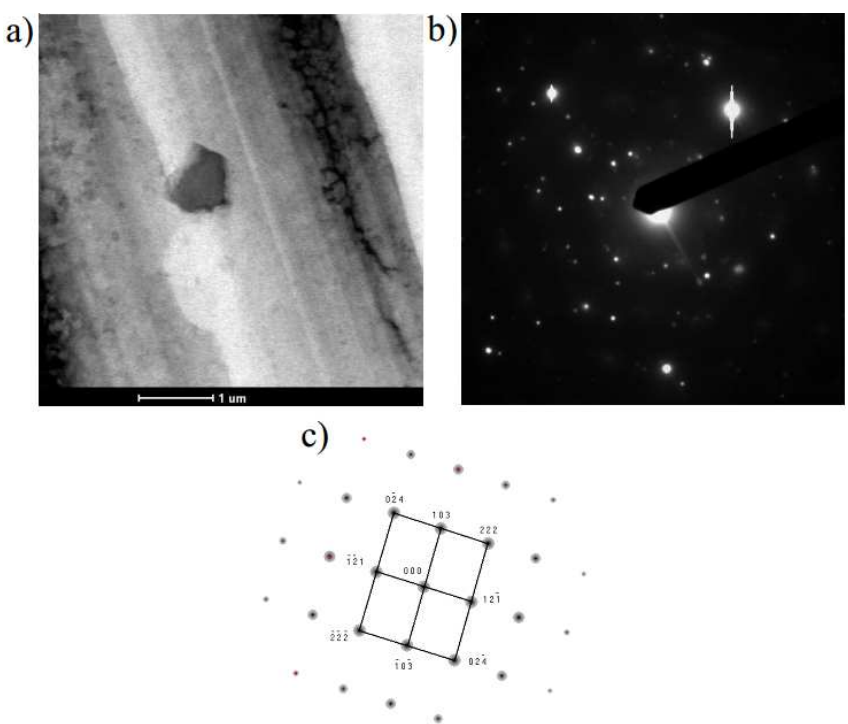

Fig. 3. $\mathrm{Al}_{2} \mathrm{Sr}$ particle in the $\mathrm{Zn}$ matrix, bright field (a), diffraction pattern $(b)$, solution of the diffraction pattern for the $\mathrm{Al}_{2} \mathrm{Sr}$ phase (c). 
The EDS area analysis, shown in Fig. 4, presents the chemical composition of the area in form of elements mappings, there are clearly visible the changes of the aluminium and zinc concentrations. In case of copper distribution the concentration fluctuations indicate the presence of other phases.
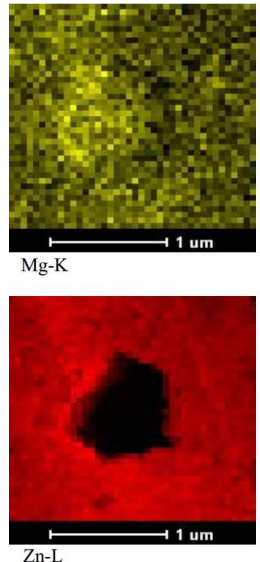

Fig. 4. EDS microanalysis of the investigated $\mathrm{Zn}$ al loy with maps of elements' distribution. Image of the secondary electrons is presented in Fig. 3.

The structural investigations allows also to compare the microstructure as well as the structural features, like edge dislocations, grain boundaries or high resolved subgrains microstructure. These feature are shown in Figs. 5-8. The results allow to state that with addition of strontium the structure changes in a significant way, and that there is a relative huge difference between non-modified and modified material treated with forced cooling with $0.2^{\circ} \mathrm{C} \mathrm{s}^{-1}$.

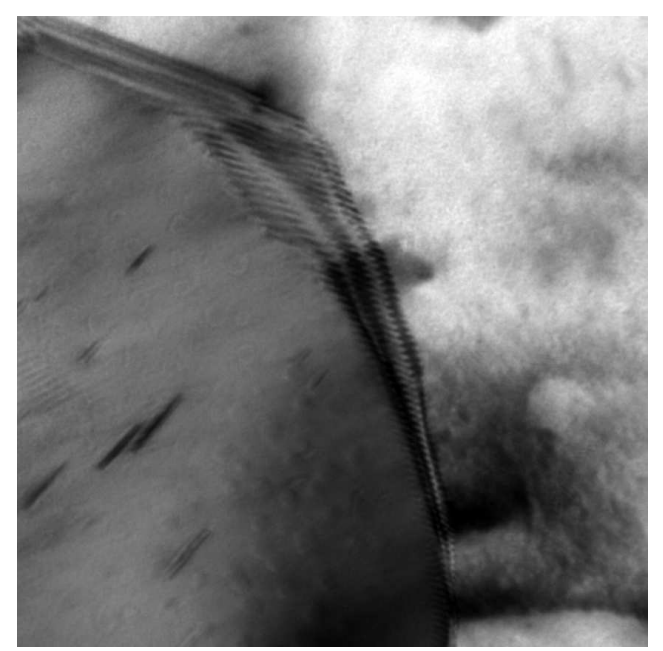

Fig. 5. Edge dislocation on the grain boundary of the Sr modified zinc.

The obtained results from the microstructure investigation performed on TEM reveals the occurring polycrystalline microstructure of the remelted $\mathrm{Zn}-\mathrm{Al}-\mathrm{Cu}$ alloy (Fig. 5) as well as the presence of micro-eutectic in form

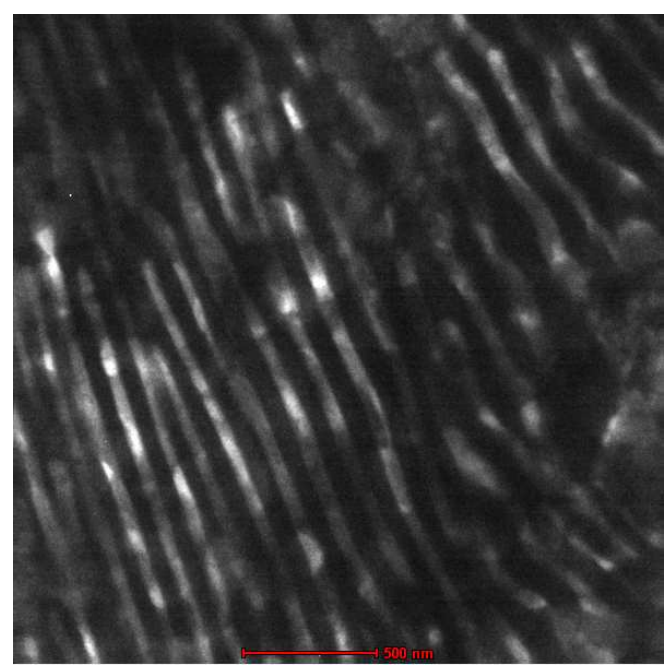

Fig. 6. Micro-eutectic in the Sr modified Zn structure.

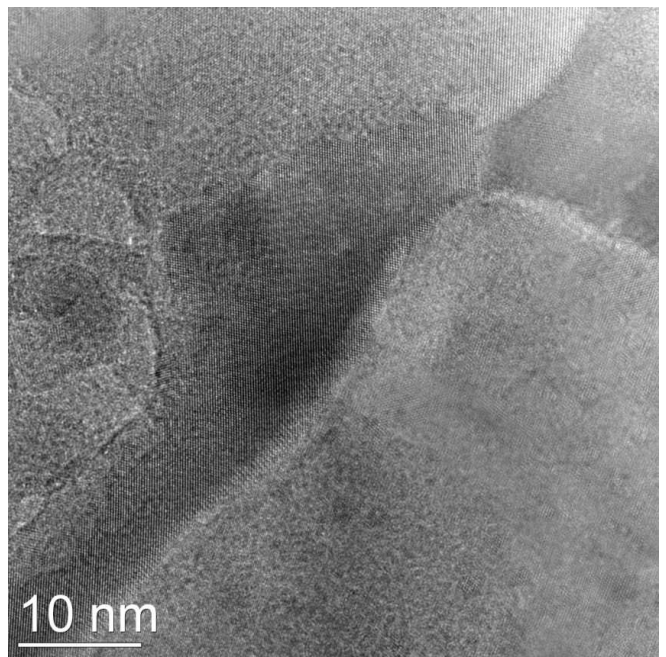

Fig. 7. Edge dislocations on the grain boundaries.

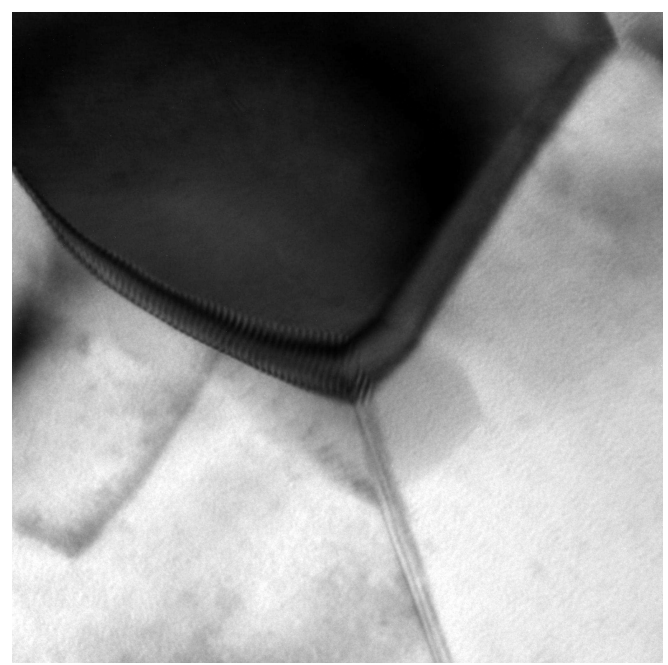

Fig. 8. Structure image of the subgrains boundaries. 
of a "tweeded" structure (Fig. 6), as a possible variant of monotektoid transformation, having an influence on GB's in the structure. Figures 7 and 8 show also two grains at a resolution where the lines are closely related to planes of atoms in the crystalline lattice. One grain boundary is being depicted as a series of edge dislocations.

Figure 9 shows the obtained cooling curves and derivative curves of the investigated alloys. The addition of $\mathrm{Sr}$ causes a change in the derivative curve which affects the position of the characteristic points of the beginning and end of phases and eutectic solidification. The main effect of strontium addition is the enhancement of the $T_{\text {sol }}$ temperature of the $\mathrm{Al}_{2} \mathrm{Sr}$ phase solidification. Changes in the form of the derivative curve has an impact also on area under the curve and the ratio of the various phases and eutectic depending on chemical composition and the cooling rate. Based on the thermo-derivative diagram, a small peak can be recognised, corresponding to the strontium containing phase solidification its solidification start temperature as well as its solidification end temperature.

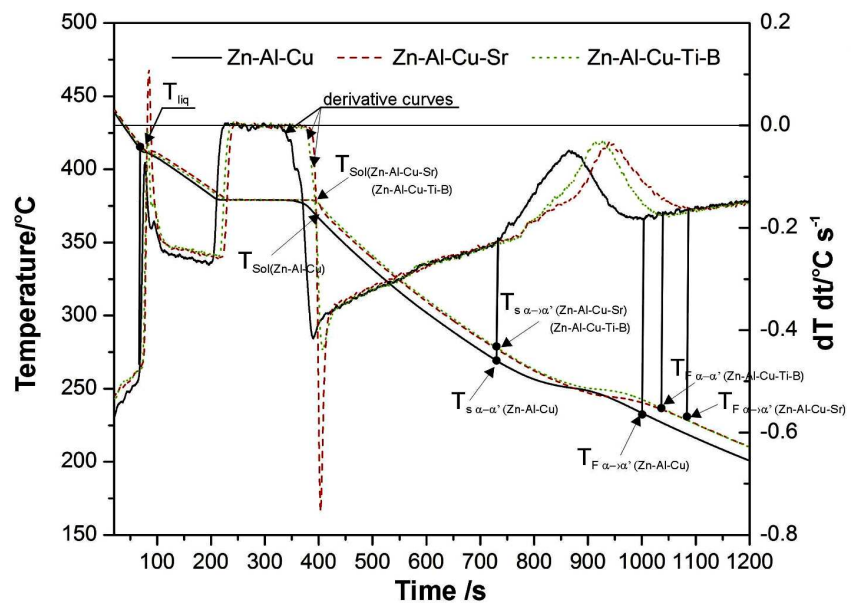

Fig. 9. Cooling curves and derivative curves for the investigated $\mathrm{Zn}$ alloy with strontium addition, cooled with the rate of $0.2^{\circ} \mathrm{C} \mathrm{s}^{-1}$.

\section{Conclusions}

The investigations suggest an effect of high cooling rate and modification of the $\mathrm{Zn}-\mathrm{Al}-\mathrm{Cu}$ alloys with strontium. Modification of $\mathrm{Zn}-\mathrm{Al}-\mathrm{Cu}$ alloys with strontium causes morphology changes of the $\alpha^{\prime}$ phase of the dendritic and globular nature of precipitates in the "tweeded" structure. Investigations using TEM confirmed also the occurrence of the phases $\mathrm{Al}_{2} \mathrm{Sr}$, using the electron diffraction investigations using the selected area diffraction (SAD). Based on the thermo-derivative analysis it was possible to determine the temperature of the begin/end of the crystallization of the alloy and different structural compounds.

\section{References}

[1] T. Tanski, L.A. Dobrzanski, L. Cizek, Adv. Mater. Res. 15-17, 491 (2007).

[2] W.R. Osorio, C.M. Freire, A. Garcia, J. Alloys Comp. 397, 179 (2005).

[3] P. Choudhury, S. Das, J. Mater. Sci. 40, 805 (2005).

[4] M. Durman, S. Murphy, J. Mater. Sci. 32, 1603 (1997).

[5] B. Krupińska, K. Labisz, Z. Rdzawski, Arch. Mater. Sci. Eng. 55, 29 (2012).

[6] L.A. Dobrzanski, K. Labisz, M. Piec, J. Lelątko, A. Klimpel, Mater. Sci. Forum 530-531, 334 (2006).

[7] K. Labisz, Mat.-wiss. Werkstofftech. 45, 314 (2014).

[8] T. Tanski, Mat.-wiss. Werkstofftech. 45, 333 (2014).

[9] M. Krupinski, L.A. Dobrzanski, J.H. Sokolowski, W. Kasprzak, G. Byczynski, Mater. Sci. Forum 539-543, 339 (2007).

[10] L.A. Dobrzański, W. Borek, Arch. Civ. Mech. Eng. 12, 299 (2012). 